\title{
Oral mucosal lipids are antibacterial against Porphyromonas gingivalis, induce ultrastructural damage, and alter bacterial lipid and protein compositions
}

\author{
Carol L Fischer ${ }^{1}$, Katherine S Walters ${ }^{2}$, David R Drake ${ }^{1,3}$, Deborah V Dawson ${ }^{1,4}$, Derek R Blanchette ${ }^{1}$, \\ Kim A Brogden ${ }^{1,5}$ and Philip W Wertz ${ }^{1,6}$
}

Oral mucosal and salivary lipids exhibit potent antimicrobial activity for a variety of Gram-positive and Gram-negative bacteria; however, little is known about their spectrum of antimicrobial activity or mechanisms of action against oral bacteria. In this study, we examine the activity of two fatty acids and three sphingoid bases against Porphyromonas gingivalis, an important colonizer of the oral cavity implicated in periodontitis. Minimal inhibitory concentrations, minimal bactericidal concentrations, and kill kinetics revealed variable, but potent, activity of oral mucosal and salivary lipids against $P$. gingivalis, indicating that lipid structure may be an important determinant in lipid mechanisms of activity against bacteria, although specific components of bacterial membranes are also likely important. Electron micrographs showed ultrastructural damage induced by sapienic acid and phytosphingosine and confirmed disruption of the bacterial plasma membrane. This information, coupled with the association of treatment lipids with $P$. gingivalis lipids revealed via thin layer chromatography, suggests that the plasma membrane is a likely target of lipid antibacterial activity. Utilizing a combination of two-dimensional in-gel electrophoresis and Western blot followed by mass spectroscopy and N-terminus degradation sequencing we also show that treatment with sapienic acid induces upregulation of a set of proteins comprising a unique $P$. gingivalis stress response, including proteins important in fatty acid biosynthesis, metabolism and energy production, protein processing, cell adhesion and virulence. Prophylactic or therapeutic lipid treatments may be beneficial for intervention of infection by supplementing the natural immune function of endogenous lipids on mucosal surfaces.

International Journal of Oral Science (2013) 5, 130-140; doi:10.1038/ijos.2013.28; published online 19 July 2013

Keywords: antimicrobial lipid; fatty acid; Porphyromonas gingivalis; sphingoid base; sphingolipid; ultrastructure

\section{INTRODUCTION}

Infection and inflammation in the oral cavity ranges from gingivitis, a mild and reversible inflammation of the gingiva, to aggressive periodontitis, a chronic inflammation and associated exaggerated immune response ${ }^{1}$ that leads to progressive destruction of the periodontal ligament and alveolar bone. Dependent upon oral hygiene, socioeconomic status and other environmental, genetic and metabolic risk factors, periodontitis occurs in just over $47 \%$ of the population of the United States with a prevalence of $8.7,30.0$ and $8.5 \%$ for mild, moderate, and severe periodontitis, respectively. ${ }^{2}$

Porphyromonas gingivalis, one of more than 600 bacterial species found in the oral cavity, is among the most influential periodontal pathogens; $P$. gingivalis is more likely to be found in patients with periodontitis and less likely to be present in healthy individuals. ${ }^{3-5}$ Furthermore, $P$. gingivalis shows a strong positive relationship with two parameters important in the diagnosis of periodontitis: increased sulcular pocket depth and bleeding upon probing. ${ }^{3-5}$ This Gramnegative, black pigmented, strict anaerobic coccobacillus is recognized as a late colonizer in the development of oral biofilms, ${ }^{4,6}$ where the multitude of virulence factors produced by $P$. gingivalis contributes to its pathogenicity. ${ }^{7}$ Additionally, P. gingivalis produces many proteins, enzymes, and metabolic end products that are important to its survival and growth within the host because they are active against a broad spectrum of host proteins and provide mechanisms for evasion of host defenses. $^{7}$

\footnotetext{
${ }^{1}$ Dows Institute for Dental Research, College of Dentistry, The University of lowa, lowa City, USA; ${ }^{2}$ Central Microscopy Research Facility, College of Dentistry, The University of Iowa, lowa City, USA; ${ }^{3}$ Department of Endodontics, College of Dentistry, The University of lowa, lowa City, USA; ${ }^{4}$ Department of Pediatric Dentistry, College of Dentistry, The University of lowa, lowa City, USA; ${ }^{5}$ Department of Periodontics, College of Dentistry, The University of lowa, lowa City, USA and ${ }^{6}$ Department of Oral Pathology, Radiology \& Medicine, College of Dentistry, The University of lowa, lowa City, USA

Correspondence: Dr PW Wertz, Department of Oral Pathology, Radiology \& Medicine and Dows Institute for Dental Research, College of Dentistry, The University of lowa, 801 Newton Road, lowa City IA 52242, USA
}

E-mail: philip-wertz@uiowa.edu

Received 6 November 2012; accepted 22 April 2013 
Control of oral bacteria is mediated by a diverse array of specific and non-specific innate immune factors present in saliva and on mucosal surfaces. ${ }^{8-9}$ More than 45 antimicrobial proteins and peptides are grouped into functional families that include cationic peptides, metal ion chelators, histatins, defensins, bacterial adhesions and agglutinators, and enzymes directed at the bacterial cell wall. The physiological concentration of most salivary antimicrobial proteins and peptides, however, is lower than the effective concentration in vivo ${ }^{8}$ which suggests that there may be additional immune functions within the saliva.

Lipids, although less well known, are also important innate immune molecules. ${ }^{10-11}$ Saliva contains an array of lipids that include cholesterol, fatty acids, triglycerides, wax esters, cholesterol esters and squalene. ${ }^{12-15}$ These lipids contribute to a variety of cellular and immune-related processes including transport of fat-soluble antioxidants to and from the mucosal surfaces, the pro- and anti-inflammatory properties of mucosal surfaces, and the innate antimicrobial activity of mucosal surfaces. ${ }^{16-18}$ Sphingoid bases and short chain fatty acids, of epithelial and sebaceous gland origin, are found within the saliva, the stratum corneum of the gingiva and hard palate, and the mucosal epithelium. These sphingoid bases and short chain fatty acids exhibit antimicrobial activity against a variety of Gram-positive and Gramnegative bacteria. ${ }^{10,19-22}$ Recent work suggests these lipids are also likely involved in innate immune defense against epidermal and mucosal bacterial infections. ${ }^{11,14}$ However, relatively little is known about the spectrum of lipid activity against oral bacteria or the mechanisms of action.

In this study, we examine the antimicrobial activity of sphingoid bases: sphingosine, dihydrosphingosine and phytosphingosine, and fatty acids: sapienic acid and lauric acid, commonly found within the oral cavity, against $P$. gingivalis. We also explore potential mechanisms of action for select lipid-organism combinations and present their potential as pharmaceuticals to improve therapies for treatment of mucosal infections and inflammatory disorders.

\section{MATERIALS AND METHODS}

\section{Bacterial species and growth conditions}

P. gingivalis strain 381 was cultured in Tryptic Soy Broth (Difco Laboratories, Detroit, MI, USA) supplemented with vitamin $\mathrm{K}_{1}$ and hemin (Sigma Chemical Co., St Louis, MO, USA) and incubated at $37{ }^{\circ} \mathrm{C}$ in an anaerobic chamber (Coy Laboratory Products Inc., Grass Lake, MI, USA) containing an atmosphere of $85 \% \mathrm{~N}_{2}, 10 \% \mathrm{H}_{2}$ and $5 \%$ $\mathrm{CO}_{2}$. Unless otherwise noted, we transferred cells to fresh medium and grew them overnight before adjusting to contain $1 \times 10^{8} \mathrm{CFU} \cdot \mathrm{mL}^{-1}$ (optical density (OD) 0.108, $600 \mathrm{~nm}$; Spectronic 20D+; Thermo Fisher Scientific Inc., Waltham, MA, USA) and then diluting to a concentration of $1 \times 10^{7} \mathrm{CFU} \cdot \mathrm{mL}^{-1}$. Unless otherwise noted, controls for all assays included medium only (sterility control), $P$. gingivalis samples treated with $0.14 \mathrm{~mol} \cdot \mathrm{L}^{-1} \mathrm{NaCl}$ (negative treatment control and positive growth control), sheep myeloid antimicrobial protein (SMAP28) (positive control) and chlorhexidine (positive control).

\section{Preparation of lipids}

Phytosphingosine, D-sphingosine (e.g. sphingosine), D-erythrodihydrosphingosine (e.g. dihydrosphingosine) and lauric acid were obtained from Sigma Chemical Co. Sapienic acid was obtained from Matreya Inc. (Pleasant Gap, PA, USA). We dissolved lipids in a chloroform : methanol solution $(2: 1)$ and confirmed purity by thin-layer chromatography (TLC). Lipids, dried under nitrogen, were then mixed with sterile $0.14 \mathrm{~mol} \cdot \mathrm{L}^{-1} \mathrm{NaCl}$ to make a $1.0 \mathrm{mg} \cdot \mathrm{mL}^{-1}$ stock solution, sonicated for 30 minutes in a $37{ }^{\circ} \mathrm{C}$ bath sonicator (Branson
2200, Hayward, CA, USA) in five minute increments to suspend the lipid, and diluted to the desired concentration using $0.14 \mathrm{~mol} \cdot \mathrm{L}^{-1} \mathrm{NaCl}$.

Sheep myeloid antimicrobial protein (SMAP28), a cathelicidin effective against many bacteria and fungi, ${ }^{23}$ was included in this study as a positive control to show that the microdilution assays were set up properly and minimal inhibitory concentrations were accurate and within previously reported ranges. ${ }^{24-25}$ SMAP28 was synthesized as previously described ${ }^{23}$ by NeoMPS Inc. (San Diego, CA, USA) and suspended in $0.14 \mathrm{~mol} \cdot \mathrm{L}^{-1} \mathrm{NaCl}$ for all assays.

\section{Antimicrobial assay}

Using broth microdilution assays, we determined the minimum inhibitory concentration (MIC) for each bacteria-lipid combination. ${ }^{26}$ We serially diluted lipids in $0.14 \mathrm{~mol} \cdot \mathrm{L}^{-1} \mathrm{NaCl}$ (500$1 \mu \mathrm{g} \cdot \mathrm{mL}^{-1}$ ) in microtiter plates (Immunolon 1 microtiter plates; Thomas Scientific, Swedesboro, NJ, USA) and added $P$. gingivalis at a concentration of $1 \times 10^{7} \mathrm{CFU} \cdot \mathrm{mL}^{-1}$. After incubation for five days as described above, we read the OD $(\lambda=600 \mathrm{~nm})$ of bacterial growth in a spectrophotometer (Spectromax Microplate Reader; Molecular Devices Corp., Sunnyvale, CA, USA) and determined the MIC, defined as the lowest concentration of peptide or lipid that reduced growth by more than $50 \%$ (relative to the positive controls).

Minimum bactericidal concentrations (MBCs), defined as the lowest concentration of peptide or lipid that completely killed all bacteria in a suspension, were determined by plating bacteria from the completed broth microdilution assays onto CDC formulation anaerobic $5 \%$ sheep blood agar plates (Remel, Lenexa, KS, USA). We incubated plates for seven days as described above before examination of the plates for the presence of CFU.

\section{Kill kinetics}

Using the spiral plating method, ${ }^{27}$ we assessed kill kinetics for each lipid against $P$. gingivalis. For this, we prepared a $1 \times 10^{7} \mathrm{CFU} \cdot \mathrm{mL}^{-1}$ suspension of $P$. gingivalis, divided this suspension into tubes for each treatment and added either $0.14 \mathrm{~mol} \cdot \mathrm{L}^{-1} \mathrm{NaCl}$, SMAP28, clorhexidine, or each of the lipids at a concentration equivalent to $10 \times$ the MIC determined in the broth microdilution assays. At time intervals of $0,0.5,1,2,3,4,6,8$ and $24 \mathrm{~h}$, we serially diluted one-ml samples from each treatment into $0.14 \mathrm{~mol} \cdot \mathrm{L}^{-1} \mathrm{NaCl}$ and plated the diluted samples onto CDC formulation anaerobic 5\% sheep blood agar plates (Remel) using an Autoplate 4000 Automated Spiral Plater (Advanced Instruments Inc., Norwood, MA, USA). After incubating for 7 days we counted the CFU and calculated concentrations.

\section{Ultrastructural analyses of lipid-exposed bacterial cells}

Broth cultures of $P$. gingivalis were adjusted to $1 \times 10^{7} \mathrm{CFU} \cdot \mathrm{mL}^{-1}$ in growth media as described above, and treated with $80 \mu \mathrm{g} \cdot \mathrm{mL}^{-1}$ phytosphingosine, $586 \mu \mathrm{g} \cdot \mathrm{mL}^{-1}$ sapienic acid, $50 \mu \mathrm{g} \cdot \mathrm{mL}^{-1}$ SMAP28 or $0.14 \mathrm{~mol} \cdot \mathrm{L}^{-1} \mathrm{NaCl}$ for $1 \mathrm{~h}$. To visualize cells in various stages of death, we based incubation times on kill kinetics so that each suspension contained both viable $(<50 \%)$ and non-viable $(\geqslant 50 \%)$ cells.

For examination by transmission electron microscopy (TEM), treated $P$. gingivalis were fixed in $2.5 \%$ glutaraldehyde in $0.1 \mathrm{~mol} \cdot \mathrm{L}^{-1}$ sodium cacodylate buffer, $\mathrm{pH} 7.4$, for $1 \mathrm{~h}$ in an ice bath, and washed twice in $0.1 \mathrm{~mol} \cdot \mathrm{L}^{-1}$ sodium cacodylate buffer $(\mathrm{pH} 7.4$ ) for $20 \mathrm{~min}$. We then pelleted the bacteria by centrifugation, suspended the cells in warm $0.9 \%$ agarose in $0.1 \mathrm{~mol} \cdot \mathrm{L}^{-1}$ sodium cacodylate buffer, $\mathrm{pH} 7.4$, and allowed the agarose to congeal before dicing it into $1-\mathrm{mm}$ cubes. After two washes in $0.1 \mathrm{~mol} \cdot \mathrm{L}^{-1}$ sodium cacodylate buffer, $\mathrm{pH} 7.4$, for $20 \mathrm{~min}$, we treated the cubes with $1 \%$ osmium tetroxide for $1 \mathrm{~h}$, 
washed them again in $0.1 \mathrm{~mol} \cdot \mathrm{L}^{-1}$ sodium cacodylate buffer, and then dehydrated the cubes in a series of $30 \%, 50 \%, 70 \%, 95 \%$ and absolute ethanol solutions. After clearing in propylene oxide, we infiltrated the cubes with a propylene oxide-Epon mixture $(1: 1)$, embedded them in Epon, and polymerized at $60{ }^{\circ} \mathrm{C}$ for $48 \mathrm{~h}$. Finally, we cut ultrathin sections from each cube, placed sections on formvar-coated nickel grids, and stained with 5\% uranyl acetate and Reynold's lead citrate. We examined samples for intracellular damage using a JEOL TEM1230 transmission electron microscope (JEOL USA Inc., Peabody, MA, USA).

For examination by scanning electron microscopy (SEM) treated or untreated $P$. gingivalis were layered on a nucleopore membrane (SPI Supplies, West Chester, PA, USA), fixed in $2.5 \%$ glutaraldehyde in $0.1 \mathrm{~mol} \cdot \mathrm{L}^{-1}$ sodium cacodylate buffer $(\mathrm{pH} 7.4)$ for $1 \mathrm{~h}$ in an ice bath, and washed twice in $0.1 \mathrm{~mol} \cdot \mathrm{L}^{-1}$ sodium cacodylate buffer $(\mathrm{pH} 7.4)$ for $4 \mathrm{~min}$. We then further fixed samples with $1 \%$ osmium tetroxide for $30 \mathrm{~min}$, washed them twice in double distilled water, and then dehydrated them in a series of $25 \%, 50 \%, 75 \%, 95 \%$ and absolute ethanol solutions followed by hexamethyldisilizane. After mounting the membranes containing bacteria onto stubs, we sputter coated them with gold and palladium, and examined each sample for surface damage using a Hitachi S-4800 field emission scanning electron microscope (Hitachi High-Technologies Canada Inc., Toronto, Ont., Canada).

\section{Lipid analysis}

Broth cultures of $P$. gingivalis were incubated with each of sphingosine, dihydrosphingosine, phytosphingosine, sapienic acid, lauric acid and $0.14 \mathrm{~mol} \cdot \mathrm{L}^{-1} \mathrm{NaCl}$ at $500 \mu \mathrm{g} \cdot \mathrm{mL}^{-1}$ (total volume of each treatment was $5 \mathrm{~mL}$ ) for $1.5 \mathrm{~h}$ at $37^{\circ} \mathrm{C}$. After treatment with lipids, we divided each sample and processed half for lipid analysis and half for protein analysis (next section). Before pelleting by centrifugation, bacteria were killed by adding $0.05 \%$ sodium azide. After freezing these whole-cell pellets at $-80^{\circ} \mathrm{C}$, we lyophilized the bacteria, and extracted the lipids using a previously described method ${ }^{28}$ consisting of successive extractions of chloroform:methanol mixtures $(2: 1,1: 1$ and $1: 2)$ at room temperature. Extracted lipids were recovered by evaporation of the solvent under a stream of nitrogen. To purify the samples, we redissolved each sample in $5 \mathrm{~mL}$ chloroform:methanol $(2: 1)$ and washed the solution with $1 \mathrm{~mL} 2 \mathrm{~mol} \cdot \mathrm{L}^{-1}$ potassium chloride $(20 \%, V / V)$ to remove salts and other water soluble materials. ${ }^{29}$ The resulting upper phase was discarded and the lower phase, containing purified lipids, was again dried under nitrogen. The dried lipids were reconstituted in chloroform:methanol, $2: 1$ at a concentration of $10 \mathrm{mg} \cdot \mathrm{mL}^{-1}$. Additional controls included suspensions of each treatment lipid in sterile bacterial growth medium followed by centrifugation and resuspension in chloroform:methanol $(2: 1)$ to test the ability of each lipid to sediment or adhere to the tube, which would cause false positive results.

The lipids from each treatment and control were separated by quantitative TLC as previously described. ${ }^{30}$ We obtained glass-backed plates coated with a $250 \mu \mathrm{m}$ thickness of silica $\mathrm{G}$ gel (Alltech Associates, Deerfield, IL, USA) and prepared the plates by washing with chloroform:methanol $(2: 1)$ to remove organic contaminants. Plates were then air-dried and activated in a $110^{\circ} \mathrm{C}$ oven. After dividing the silica gel $G$ plates into six-mm wide lanes, we spotted total extracted lipids from each sample onto the lanes and developed these chromatograms differentially for each lipid class.

Chromatograms for separation of sphingoid bases were developed in chloroform: methanol: water $(40: 10: 1)$. Sphingosine served as a standard for quantification. ${ }^{31}$ For separation of fatty acids, chromatograms were developed in three sequential solvents/mixtures: (i) n-hexane; (ii) toluene; and (iii) hexane: ethyl-ether : acetic acid (70:30:1). A standard containing squalene, cholesterol esters, wax esters, triglycerides, fatty acids and cholesterol was used to identify migration of the fatty acids. For development of chromatograms, we sprayed each plate with $50 \%$ sulfuric acid and charred the lipid bands by heating slowly to $220{ }^{\circ} \mathrm{C}$ on a hotplate. Digital images were obtained using a Hewlett-Packard Scanjet 3500c and analyzed using TNIMAGE (Thomas Nelson, Bethesda, MD, USA) in strip densiometry mode to estimate the total extracted lipid weight in each of the treated and untreated bacterial samples as well as controls. To calculate the percentage of lipid uptake for each sample we divided the total extracted lipid weight by the total weight of lipid added to each sample. Because $P$. gingivalis plasma membrane naturally contains dihydrosphingosine, ${ }^{32-35}$ total sphingoid base lipids were normalized by subtracting the total sphingoid base weight present in the untreated P. gingivalis controls.

\section{Protein analyses}

For analysis by reducing-sodium dodecyl sulfate (SDS)-polyacrylamide gel electrophoresis (PAGE), lipid-treated and untreated $P$. gingivalis samples (remaining from samples processed for lipid analysis), suspended in SDS reducing sample buffer, were sonicated in a bath sonicator five times at $3 \mathrm{~min}$ each time, cooling on ice between each sonication event, before boiling for $8 \mathrm{~min}$. After denaturing the proteins, we loaded the samples onto a NuPage $4 \%-12 \%$ BisTris $1.5 \mathrm{~mm}$ gel (Life Technologies, Grand Island, NY, USA) and separated the protein fractions using the XCell SureLock Mini-Cell Electrophoresis System (Invitrogen, Carlsbad, CA, USA) in a buffer system of NuPage 1X MOPS SDS running buffer and 0.1\% NuPage antioxidant (Life Technologies, Grand Island, NY, USA). We used Novex Sharp Protein Standards as size markers (Life Technologies, Grand Island, NY, USA).

Protein bands were then visualized using the GenScript eStain Protein Staining System (Piscataway, NJ, USA) or transferred onto polyvinylidene difluoride membranes (Life Technologies, Grand Island, NY, USA) for Western blot analysis using the XCell II Blot Module Western Blot system (Invitrogen, Carlsbad, CA, USA) in a buffer of NuPage 1X transfer buffer with $0.1 \%$ antioxidant (Life Technologies, Grand Island, NY, USA). After transfer of proteins to the polyvinylidene difluoride membrane, we visualized proteins using a 0.1\% Coomassie Brilliant Blue R-250 stain (Sigma Chemical Co., St Louis, MO, USA) in $40 \%$ methanol and $10 \%$ acetic acid, followed by destaining in methanol: acetic acid : water solutions $(40: 10: 50$, then $90: 5: 5$ ). Bands of interest were excised and sequenced (Protein Facility, Iowa State University, Ames, IA, USA) by the Edman Nterminus degradation process and BLAST searches of the National Center for Biotechnology Information (NCBI) P. gingivalis protein database identified upregulated protein bands of interest.

In addition, we used two-dimensional in-gel electrophoresis (2DDIGE) (Applied Biomics, Hayward, CA, USA) to compare proteins present in sapienic acid-treated and untreated P. gingivalis. For 2D-DIGE, treated and untreated samples were labeled with different fluorescent dyes, mixed, and then separated first by isoelectric point, followed by molecular weight separation. From the resulting gels, we chose 16 spots indicative of upregulated proteins in the sapienic acid-treated sample for sequencing by mass spectroscopy. Sequences were identified by an NCBInr BLAST search of the $P$. gingivalis protein database.

\section{Cytotoxicity}

The cytotoxicity of sphingosine, phytosphingosine, dihydrosphingosine and glycerol monolaurate was determined using Alamar Blue 
(AlamarBlue; Invitrogen, Carlsbad, CA, USA). Briefly, $200 \mu \mathrm{L}$ of a keratinocyte suspension containing $1 \times 10^{5}$ cells $\cdot \mathrm{mL}^{-1}$ (normal human keratinocytes in KBM-Gold; Lonza Walkersville Inc., Walkersville, MD, USA) was put into the wells of a microtiter plate and incubated at $37{ }^{\circ} \mathrm{C}$ in a $5 \% \mathrm{CO}_{2}$ atmosphere to allow adherence of cells. After $2 \mathrm{~h}$, the cell culture supernatant was removed and media containing 160.0, $80.0,40.0,20.0,10.0,5.0,2.5,1.3,0.6$ and $0.3 \mu \mathrm{mol} \cdot \mathrm{mL}^{-1}$ sphingosine, phytosphingosine or dihydrosphingosine with Alamar Blue was added. Media only containing keratinocytes served as live cell controls and media containing keratinocytes heated to $56{ }^{\circ} \mathrm{C}$ for 30 min served as killed cell controls. The plates were incubated at $37{ }^{\circ} \mathrm{C}$ with $5 \% \mathrm{CO}_{2}$. At $48 \mathrm{~h}$, the plates were read in the spectrophotometer (SpectraMax M2e Multi-Mode Microplate Reader; Molecular Devices, LLC, Sunnyvale, CA, USA) and the fluorescence intensity was determined using an excitation wavelength of 530-560 $\mathrm{nm}$ and an emission wavelength of $590 \mathrm{~nm}$. Cytotoxicity was defined as the (fluorescence intensity of the test long chain base dilution/fluorescence intensity of the live cell control $) \times 100 \%$. The lethal dose $50\left(\mathrm{LD}_{50}\right)$ was determined where the $50 \%$ point intercepts the dose response curve to the concentration along the $x$-axis.

\section{Statistical analyses}

Preliminary evaluation of MIC, MBC and kill kinetics data using the Shapiro-Wilk procedure provided strong evidence of departure from normality; consequently, non-parametric procedures were used throughout. The Kruskal-Wallis test was employed to detect treatment differences in MIC and MBC distribution; the adaptation of the Tukey method due to Conover ${ }^{36}$ was used to adjust for multiple pairwise comparisons of lipid treatment groups in conjunction with an overall $5 \%$ level of significance.

Two summary measures of kill kinetics were computed for comparison of longitudinal data between treatment groups. Trapezoidal area under the curve (AUC) was used as a summary measure of bacterial variability over the treatment time course ${ }^{37-38}$ where larger AUC values correspond to greater viability. Comparisons were made with and without the inclusion of AUCs from the control sample. A second summary measure of kill kinetics over time considered was time to zero, defined as the first time point at which total bacterial counts reached zero (complete killing). Because samples sizes were modest, the overall test for treatment differences for these two outcomes was conducted using exact Kruskal-Wallis tests. Pair-wise comparisons were made using exact Wilcoxon Rank Sum tests with Bonferroni correction for multiple comparisons, again in conjunction with an experiment-wise Type I error level of 5\%. Note that, for certain of these longitudinal assays (i.e., from a given vial), none of the bacterial counts in the series reached zero. In such instances, the value of the corresponding time to zero was assigned the highest rank for purposes of analysis. If several such instances occurred in a given analysis, ties corresponding to the highest rank were assigned.

\section{RESULTS}

All lipids exhibited antimicrobial activity against $P$. gingivalis with variability in the activity across lipids. Sphingoid bases ranged in MIC from 0.2 to $0.8 \mu \mathrm{g} \cdot \mathrm{mL}^{-1}$, while fatty acids MICs ranged from 58.6 to $125.0 \mu \mathrm{g} \cdot \mathrm{mL}^{-1}$ (Table 1 ). Distribution of both MIC and $\mathrm{MBC}$ values differed among the treatment groups $(P<0.0001)$ and all 10 pairwise comparisons were significantly different for MICs $(P$ values $<0.0001-0.0014)$ and MBCs ( $P$ values $<0.0001-0.0002)$. MICs for all three sphingoid bases against $P$. gingivalis were lower than SMAP28 and chlorhexidine MICs and were far below the $\mathrm{LD}_{50}$
Table 1 Minimum lipid concentrations required to inhibit or kill $\boldsymbol{P}$. gingivalis. Pairwise comparisons showed that all MIC and MBC values for lipid treatments were significantly different from each other $(5 \%$ level of statistical significance)

\begin{tabular}{lcc}
\hline & \multicolumn{2}{c}{ Mean $^{\mathrm{a}} \pm \mathrm{s} . \mathrm{d}$. (median) of concentration $/\left(\mu \mathrm{g} \cdot \mathrm{mL}^{-1}\right)$} \\
\cline { 2 - 3 } Compounds & MIC & MBC \\
\hline Sphingosine & $0.2 \pm 0.8(0.2)$ & $0.3 \pm 0.0(0.3)$ \\
Phytosphingosine & $0.8 \pm 0.3(0.8)$ & $1.0 \pm 0.0(1.0)$ \\
Dihydrosphingosine & $0.4 \pm 0.2(0.4)$ & $0.5 \pm 0.2(0.6)$ \\
Sapienic acid & $58.6 \pm 11.0(58.6)$ & $62.5 \pm 0.0(62.5)$ \\
Lauric acid & $125.0 \pm 0.0(125.0)$ & $218.8 \pm 57.9(250.0)$ \\
SMAP-28 & $5.0 \pm 0.0(5.0)$ & $20.0 \pm 0.0(20.0)$ \\
Chlorhexidine & $3.9 \pm 0.0(0.0)$ & $7.8 \pm 0.0(0.0)$ \\
\hline
\end{tabular}

$\mathrm{MBC}$, minimum bactericidal concentration; MIC, minimum inhibitory concentration.

${ }^{\text {a }}$ Mean \pm standard deviation (median); $n=8$ per lipid treatment.

${ }^{b}$ SMAP28 and chlorhexidine were used as positive controls to show that the microdilution assays were set up properly and MICs/MBCs were accurate and within previously reported ranges; SMAP28 and chlorhexidine results were not included in the statistical analysis.

of sphingosine (23.68 $\pm 1.76 \mathrm{SEM} \mathrm{LD}_{50}$ ), phytosphingosine (55.72 \pm 5.59 SEM $\left.\mathrm{LD}_{50}\right)$ and dihydrosphingosine $\left(33.59 \pm 6.60 \mathrm{SEM}, \mathrm{LD}_{50}\right)$ for human keratinocytes.

Sapienic acid rapidly killed $P$. gingivalis, with complete death occurring before the first sampling time of six minutes (Figure 1). The remaining lipid treatments greatly reduced the bacterial count within six minutes with complete killing occurring in almost all instances within thirty minutes. Phytosphingosine had the longest time to zero

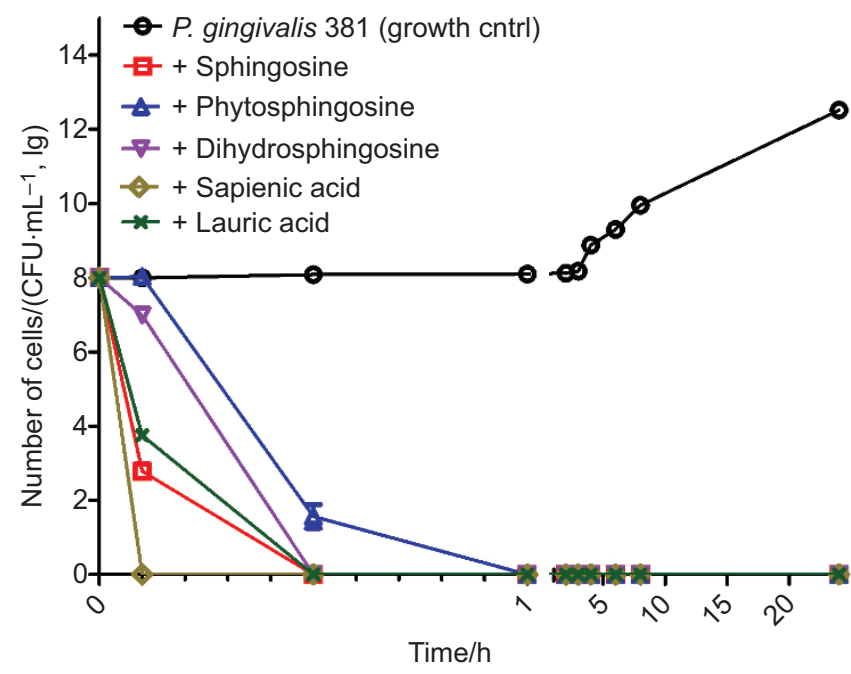

Figure 1 Kill kinetics for all lipid treatments against $P$. gingivalis. Geometric mean of $n=6$ is shown for each data point. Error bars represent the SEM; where error bars are not evident, the SEM was zero. All treatments were started at a CFU equal to the control; therefore, time zero is equal to that of the control before adding treatment. Where no bacteria were recovered, +1 was added to zero values before log transformation of the data. Trapezoidal area under the curve was calculated as a summary measure of $P$. gingivalis viability over the time interval 0.1-24 h. AUC values of: control-574.0; sphingosine-1.3; phytosphingosine - 5.3; dihydrosphingosine-3.2; sapienic acid-0.0; and lauric acid -1.7 were obtained. All pairwise treatment differences were significant $(P<0.002$ 2) after adjustment for multiple pairwise comparisons. AUC, area under the curve; SEM, scanning electron microscopy. 

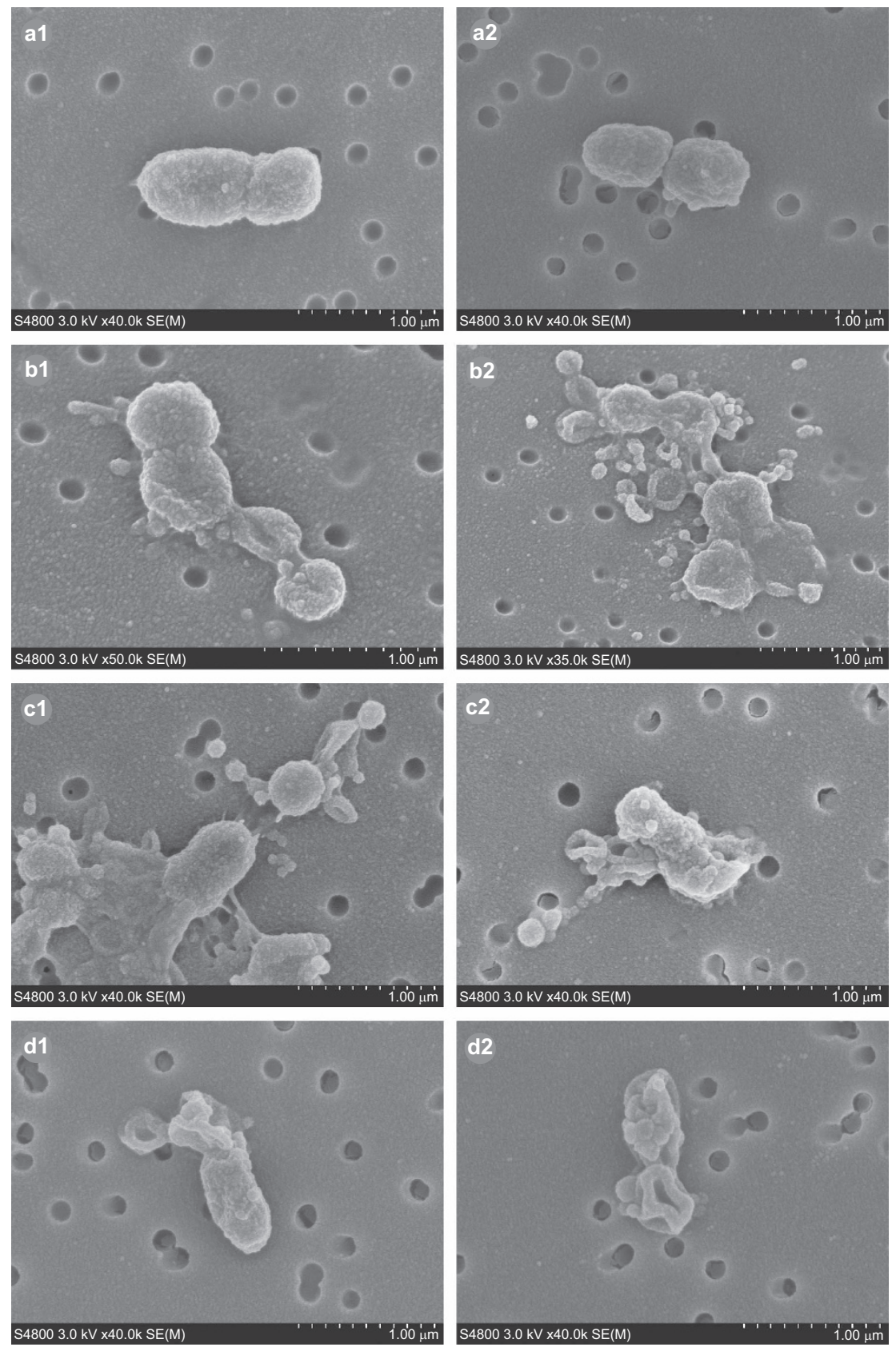

Figure 2 SEM images showing the effects of sphingoid base and fatty acid treatments on $\boldsymbol{P}$. gingivalis. Untreated cells (a1, a2) exhibit morphology typical of $P$. gingivalis Gram-negative coccobacilli. One hour treatments of $P$. gingivalis with phytosphingosine (b1, b2), sapienic acid (c1, c2) or SMAP28 (d1, d2) resulted in evidence of cellular distortion relative to the untreated bacterium including concave and rugate cells, closer aggregation of cells and/or lysis, some with detached pieces of membrane lying adjacent to the cells. SEM, scanning electron microscopy.

at $1 \mathrm{~h}$. Time to zero analyses (Supplementary Table 1) showed that sapienic acid had the shortest time to zero $(<6 \mathrm{~min})$ while phytosphingosine had the longest $(1 \mathrm{~h})$. There was strong evidence of differences among treatment groups $(P<0.0001$ in both instances $)$. Following adjustment for multiple comparisons, significant differences in time to zero were identified between sapienic acid and phytosphinogosine, as well as between these two lipids and each of the other three treatments (Supplementary Table 2). No difference was found between dihydrosphingosine, sphingosine and lauric acid, as all three treatments had a median time to zero of $30 \mathrm{~min}$.
Trapezoidal area AUC, calculated over the time interval 0.1-24 h, was 574.0 for the control; sphingosine - 1.3 ; phytosphingosine-5.3; dihydrosphingosine-3.2; sapienic acid-0.0; and lauric acid-1.7 (Supplementary Table 3). After Bonferonni adjustment (adjusted $\alpha=0.033$ ) for 15 comparisons, the outcome for each treatment was found to significantly differ from that of each of the others $(P<0.0022)$ over this time period (Supplementary Table 4).

Scanning electron micrographs demonstrated that $P$. gingivalis cells treated with phytosphingosine (Figure 2, b1 and b2) or sapienic acid (Figure 2, c1 and c2) showed various stages of lysis. Cellular debris and 

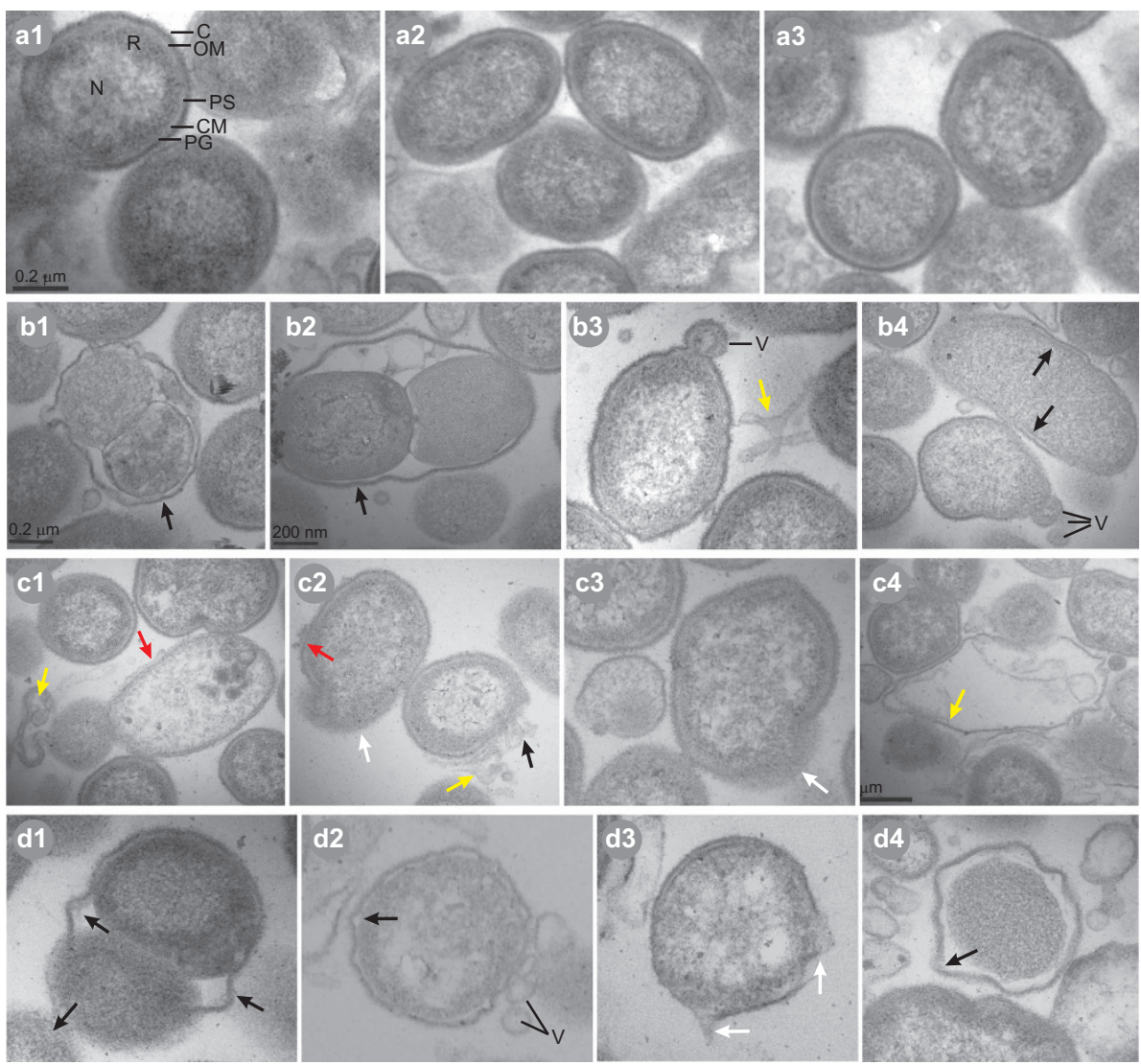

Figure 3 TEM images showing the ultrastructural effects of sphingoid bases and fatty acids on $\boldsymbol{P}$. gingivalis. Untreated cells (a1-a3) exhibited typical Gramnegative coccobacillus morphology with outer membrane (OM), capsule (C), periplasmic space (PS), peptidoglycan (PG), cellular membrane (CM), distinct nucleoid $(\mathrm{N})$ and ribosomal $(\mathrm{R})$ regions and outer membrane vesicles (V). One hour treatments of $P$. gingivalis with phytosphingosine (b1-b4), sapienic acid (c1-c4) or SMAP28 (d1-d4) resulted in cellular distortion relative to untreated bacteria. Evidence of ultrastructural damage is indicated by the colored arrows: separation of the outer membrane from the cytoplasmic membrane (red); missing pieces of membrane (black); leakage of cytoplasmic contents (white); and detached membrane lying adjacent to cells (yellow). TEM, transmission electron microscopy.

detached pieces of membrane lay adjacent to the cells. Many cells were distorted with a concave and rugate appearance and loss of cellular content. In addition, the cells were more closely aggregated and increased numbers of external blebs (relative to controls) were present on and around the bacteria. Similar to lipid-treated bacteria, SMAP28-treated P. gingivalis (Figure 2, d1 and d2) also distorted with concave and rugate morphology and was in various stages of lysis with loss of intracellular content. Untreated $P$. gingivalis (Figure 2, al and a2) cells exhibited an external structure typical of a healthy Gramnegative coccobacillus ${ }^{7}$ with multiple blebs present on the cell surface (Figure 2, a2).

Examination of untreated $P$. gingivalis thin sections by TEM (Figure 3, a1-a3) revealed typical Gram-negative morphology ${ }^{39-41}$ and internal structures were visible. All lipid-treated and SMAP28treated cells, however, exhibited intracellular damage. Detached membrane was lying adjacent to damaged cells and increased numbers of blebs (relative to controls) were present on and around the cells. Phytosphingosine (Figure 3, b1-b4) and SMAP28 (Figure 3, d1-d4) treatment induced separation of the outer membrane from the cytoplasmic membrane. Plasma membranes were compromised, with leakage of cellular contents. Both treatments also caused a loss of distinct nucleoid and ribosomal regions in many cells and a decrease in the electron density of the cytoplasmic contents. Treatment with sapienic acid (Figure 3, c1-c4) induced a different type of membrane disruption. Many sapienic acid-treated cells exhibited a bunching, or 'scrubbing', of the outer membrane. Pieces of the cell wall/membrane complex were missing in many cells and loose membrane pieces were lying adjacent to damaged cells, resulting in leakage of cellular contents.

Chromatographic separation of total lipid extracts from fatty acid or sphingoid base-treated $P$. gingivalis confirmed the presence of considerable amounts of treatment lipid in every sample relative to untreated $P$. gingivalis controls (Figure 4). P. gingivalis retained $30 \%-55 \%$ of the treatment lipids added to each sample, indicating association of both fatty acids and sphingoid bases with $P$. gingivalis lipids. Uptake of treatment lipids varied across treatments with fatty acids showing more association with bacterial lipids than sphingoid bases.

$P$. gingivalis protein expression also changed with lipid treatment. Protein analysis by SDS-PAGE revealed differential banding patterns between untreated and lipid-treated $P$. gingivalis samples (Figure 5). The most striking differences were seen with sapienic acid treatment. Further analysis of sapienic acid-treated $P$. gingivalis through Western blot and 2D-DIGE confirmed the differential expression of many proteins relative to an untreated sample. Upon sequencing of 16 upregulated protein spots from the 2D-DIGE gel (Figure 6), and seven bands from Western blots, we found proteins involved in biosynthesis of bacterial lipids, metabolism and energy production, metabolism in diverse environments, amino-acid biosynthesis, acquisition of peptides, degradation of polypeptides, cell adhesion and virulence (Table 2). 


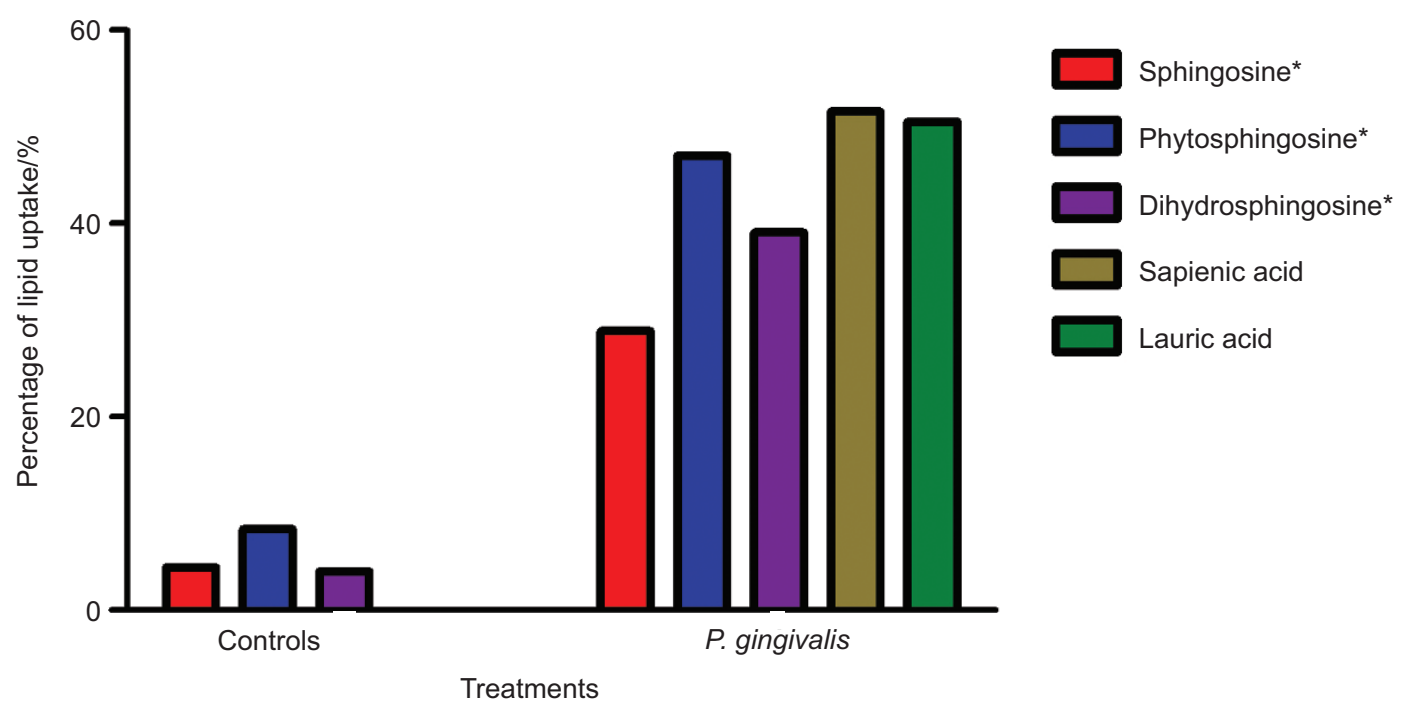

Figure 4 Association of antimicrobial lipids with P. gingivalis lipids after treatment as seen by whole cell lipid extractions and separation by TLC. Densiometry measurements of the chromatograms were used to estimate the total extracted lipid weight in each of the treated and untreated samples as well as controls. Percentage of lipid uptake by $P$. gingivalis was calculated by dividing the total extracted lipid weight by the total weight of lipid added to each sample. Because $P$. gingivalis membranes naturally contain dihydrosphingosine, we normalized the sphingoid base calculations (indicated by an asterisk) by subtracting the total sphingoid base present in untreated samples. Controls included the same concentration of lipids in media, processed along with samples to test the abilitity of the lipids to stick to the sides of the tube or pellet down with the bacteria.

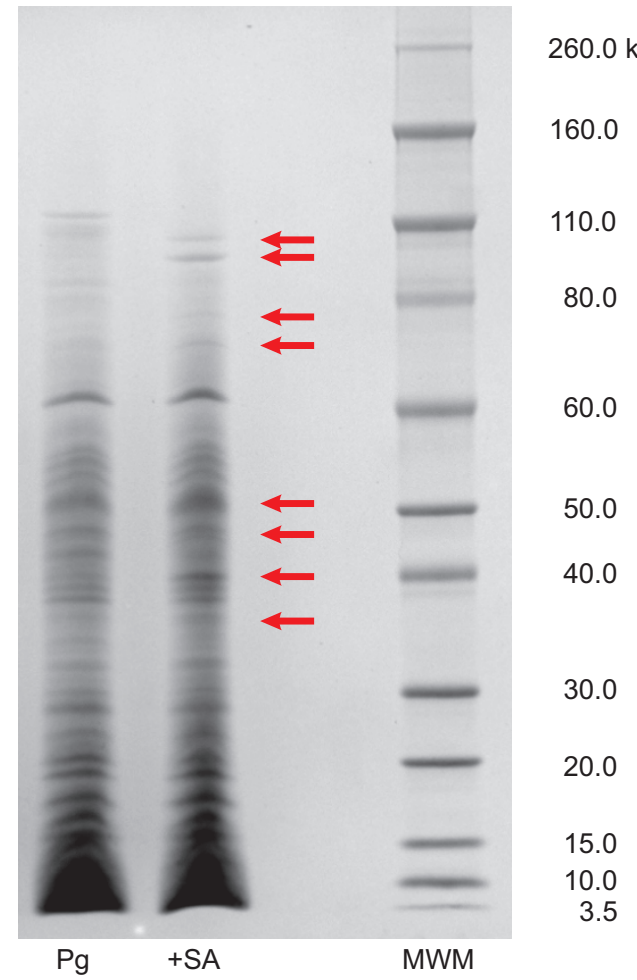

Figure 5 SDS-PAGE separation of proteins in untreated and sapienic acidtreated $\boldsymbol{P}$. gingivalis. Untreated $(\mathrm{Pg})$ and sapienic acid-treated $(+\mathrm{SA})$ proteins were separated by SDS-PAGE and visualized using Coomassie blue stain. SDSPAGE, sodium dodecyl sulfate polyacrylamide gel electrophoresis; MWM, molecular weight marker, Novex sharp protein standards.

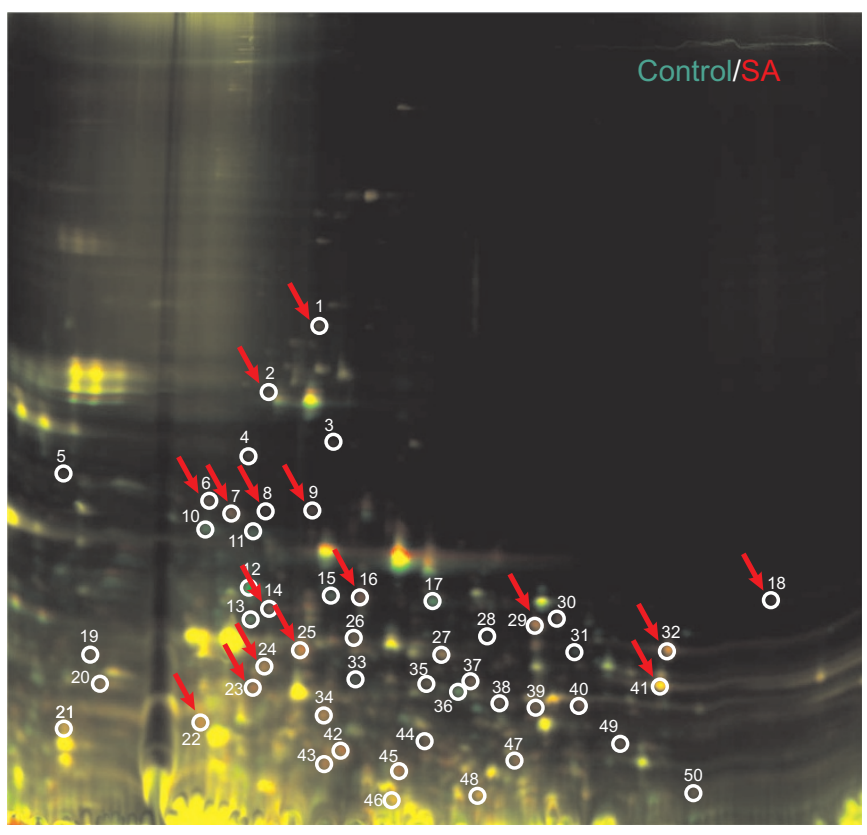

Figure 6 2D-DIGE gel showing $P$. gingivalis protein differences in untreated and sapienic acid-treated samples. Red spots indicate upregulation of proteins in treated samples and green spots indicate downregulated proteins, relative to the control sample. Yellow spots indicate colocalization (where the same proteins were present in both samples). We chose 16 spots (red arrows) for further analysis and sequenced them by mass spectroscopy. 2D-DIGE, two-dimensional ingel electrophoresis. 
Table 2 Identification of $\boldsymbol{P}$. gingivalis upregulated protiens upon treatment with sapienic acid. Identification was completed by separation by 2D-DIGE followed by sequencing by mass spectroscopy or by WB followed by sequencing via $\mathrm{N}$-terminus degradation

\begin{tabular}{|c|c|c|}
\hline Protein (identification source), gene and accession & Sequence length/aa (MW/Da) & Function and bidogical process \\
\hline 3-oxoacyl-[acyl-carrier-protein] synthase 2 (2D-DIGE) & 418 & Transferase \\
\hline$f a b F$ & $(44491.4)$ & Fatty acid biosynthesis; fatty acid elongation; lipid synthesis \\
\hline \multicolumn{3}{|l|}{ gi|34541387 } \\
\hline 3-oxoacyl-[acyl-carrier-protein] synthase 3 (KASIII) (2D-DIGE) & 335 & Transferase \\
\hline $\mathrm{fabH}$ & (37 174.4) & Fatty acid biosynthesis, elongation; lipid synthesis \\
\hline \multicolumn{3}{|l|}{ FABH_PORGI } \\
\hline NAD-dependent Glutamate dehydrogenase (GDH) (2D-DIGE \& WB) & 437 & Oxidoreductase \\
\hline gdh & (48 218.8) & Cellular amino acid metabolic processes (R, P, A, D, and E); \\
\hline gi|334146994; AAA50985 & & $\begin{array}{l}\text { nitrogen metabolism, virulence (cytotoxic by-products); } \\
\text { glutamate energy metabolism; degradation of amino acids } \\
\text { (energy source) }\end{array}$ \\
\hline Glyceraldehyde 3-phosphate dehydrogenase, type I (2D-DIGE) & 336 & Oxidoreductase/NAD binding \\
\hline gapA & (35 992.4) & Microbial metabolism in diverse environments; glycolysis/ \\
\hline gi|34541701 & & gluconeogenesis; biosynthesis of secondary metabolites \\
\hline Phosphoserine aminotransferase (2D-DIGE) & 360 & Aminotransferase \\
\hline serC & $(40090.6)$ & Microbial metabolism in diverse environments; methane \\
\hline gi|334147974 & & $\begin{array}{l}\text { metabolism; amino acid metabolism (G, S and T); amino acid } \\
\text { biosynthesis (S) }\end{array}$ \\
\hline $\begin{array}{l}\text { Arginine-specific cysteine proteinase (RGP-1; RgpA; Gingipain A) } \\
\text { (2D-DIGE) }\end{array}$ & 991 & $\begin{array}{l}\text { Virulence; acquisition of peptides; metabolism; protein } \\
\text { processing }\end{array}$ \\
\hline $\operatorname{rgp} A ; \operatorname{prtT}$ & (108 713.3) & \\
\hline \multicolumn{3}{|l|}{ P28784 } \\
\hline $\begin{array}{l}\text { Arginine-specific cysteine proteinase (RGP-2; RgpB; Gingipain B) } \\
\quad(2 \mathrm{D}-\mathrm{DIGE} \& \text { WB) }\end{array}$ & 736 & $\begin{array}{l}\text { Virulence; acquisition of peptides; metabolism; protein } \\
\text { processing }\end{array}$ \\
\hline $\operatorname{rgp} B$ & $(80952.1)$ & \\
\hline \multicolumn{3}{|l|}{ gil 1814394} \\
\hline Pg-II fimbriae (2D-DIGE) & 370 & Virulence; adhesion \\
\hline $\operatorname{fim} A$ & (39 307.8) & \\
\hline \multicolumn{3}{|l|}{ gi|22255316 } \\
\hline $\begin{array}{l}\text { Lysine-specific cysteine protease (Kgp; Lys-gingipain) (2D-DIGE \& } \\
\text { WB) }\end{array}$ & 1732 & Degradation of polypeptides \\
\hline kgp & $(40$ 135.6) & \\
\hline \multicolumn{3}{|l|}{ Q51817.1 } \\
\hline Hemagglutinin-like protein (2D-DIGE) & 348 & Adhesion \\
\hline gi|34540264 & $(39313.4)$ & \\
\hline Kgp/hemagglutinin (WB) & 1358 & Degradation of polypeptides; adhesion \\
\hline \multicolumn{3}{|l|}{ kgp } \\
\hline \multicolumn{3}{|l|}{ AAB49691; AAS68176 } \\
\hline Glycerate dehydrogenase (WB) & 317 & Microbial metabolism in diverse environments; biosynthesis of \\
\hline hprA & & secondary metabolites; Amino acids metabolism (G, S, T) \\
\hline YP-004509887; GI:333804114 & & \\
\hline
\end{tabular}

2D-DIGE, two-dimensional difference in-gel electrophoresis; WB, Western blot.

\section{DISCUSSION}

In this study we report for the first time, to our knowledge, that lipids endogenous to the saliva and oral mucosa are antimicrobial for $P$. gingivalis and induce novel ultrastructural damage. Sphingoid bases are more active against $P$. gingivalis than either chlorhexidine or SMAP28 in our studies as well as in other studies. ${ }^{42,43}$ We have reported that lipid activity is not only concentration-specific but is also specific for each bacteria-lipid combination. MICs and kill kinetics of these lipids for P. gingivalis and other bacteria previously tested in our laboratory, including other oral bacteria such as Streptococcus mitis, S. sanguinis and Fusobacterium nucleatum, ${ }^{44}$ show differential activity for these lipids across different bacteria. Our results are in agreement with growing evidence that fatty acids and sphingoid bases differentially kill bacteria in a dose-dependent manner and induce cellular damage. For example, Escherichia coli and Staphylococcus aureus treated with sphingosine, phytosphingosine or dihydrosphingosine exhibit extensive and differential intracellular and extracellular damage. ${ }^{45}$ Bibel and colleagues $^{10}$ also showed that sphinganine (i.e., dihydrosphingosine) treatment of $S$. aureus results in ultrastructural damage similar to antibiotic treatment, including lesions of the cell wall, membrane evaginations and leakage. In addition, treatment of Helicobacter pylori with oleic or linoleic acid exhibits altered morphology with disruption of cellular membranes and cell lysis. ${ }^{46}$

The dose-dependent and specific antimicrobial activity exhibited by each of these oral lipids against $P$. gingivalis lends credence to the proposal that sphingoid bases and fatty acids serve an innate immune function in the oral cavity. An extensive number of host innate immune factors, including anionic peptides, ${ }^{47}$ cathelicidins, ${ }^{23}$ and defensins, ${ }^{48,49}$ induce extensive damage to Gram-positive and Gramnegative bacteria similar to what we have described here. Activity of 
these previously described innate immune factors depends upon the size of the molecule, specific amino acid sequences, charge, structural conformation, hydrophobicity, and amphipathicity ${ }^{50}$ and mechanisms of action include flocculation of intracellular contents, alteration of the bacterial cytoplasmic membrane (e.g. pore formation) or inhibition of various cellular process (e.g., enzymatic activity and cell wall, nucleic acid or protein synthesis) ${ }^{50}$

Our work indicates that there may be different mechanisms involved for the activity of different lipids. Antimicrobial activity, the percentage of lipid retained by $P$. gingivalis, and ultrastructural damage are all dependent upon the specific lipid treatment. These data, combined with our observation that fatty acids and sphingoid bases, exhibit differential activity across bacterial species, ${ }^{44}$ lead us to believe that the antimicrobial activity of fatty acids and sphingoid bases is a specific interaction that depends upon characteristics of both the bacterium and a particular lipid. We propose that mechanisms for the antimicrobial activity of fatty acids and sphingoid bases against bacteria fit within four broad pathways: (i) membrane disruption by detergent activity; (ii) incorporation of lipids into the bacterial plasma membrane; (iii) transport of lipids across the bacterial membrane into the cytosol; and (iv) specific interactions between lipids and protein components of the bacterial membrane. Potential end results of fatty acid treatment have been reviewed ${ }^{51}$ and include creation of pores in the bacterial cell, alteration of the cellular membrane, lysis of the cell and disruption of various cellular processes either by interference of spatial arrangement or by direct binding to proteins.

The main site of lipid activity against $P$. gingivalis is likely the bacterial plasma membrane, possibly by incorporation of lipids into the membrane. Our results show that both fatty acids and sphingoid bases are retained by $P$. gingivalis after treatment. In addition, destruction of the membrane is evident in TEM images. This is similar to activity seen in other organisms following fatty acid and sphingoid base treatment. $S$. aureus treated with capric acid exhibits damage to the membrane but not the cell wall. ${ }^{20}$ Furthermore, L-forms of S. aureus (lacking cell walls) are relatively resistant to the lethal effects of dihydrosphingosine, suggesting that the plasma membrane is necessary for activity. ${ }^{10}$ Helicobacter pylori treated by two fatty acids, linoleic acid and oleic acid, also exhibits membrane destruction and both fatty acids incorporate into the plasma membrane, altering the phospholipid composition of H. pylori. ${ }^{46}$

Activity of fatty acids and sphingoid bases are likely dependent upon the specific phospholipid composition of the bacterial plasma membrane. In this study, we show that sphingoid bases are more active against $P$. gingivalis than a variety of other Grampositive and Gram-negative bacteria previously examined. ${ }^{44} P$. gingivalis contains several classes of novel phospholipids and branched lipids ${ }^{33-35}$ including phosphorylated dihydroceramides (a source of dihydrosphingosine). Because the $P$. gingivalis bacterial membrane contains sphingolipids, sphingoid bases may be more likely to either incorporate into the bacterial membrane or pass through the membrane. It is also possible that $P$. gingivalis could attempt to either utilize sphingoid bases for building its unique phospholipids or as an energy source. In our 2D-DIGE analysis of sapienic acid-treated $P$. gingivalis, we found upregulation of two key regulators of lipid metabolism, involved in catalyzing the condensation reaction of fatty acid biosynthesis: 3-oxoacyl-synthase-2 and 2-oxoacyl-synthase-3. Increasing production of fatty acids could serve several purposes: (i) increasing phospholipid production to repair damaged bacterial membranes; (ii) utilization of introduced fatty acids or sphingoid bases for phospholipid production (which may or may not be harmful); (iii) competition with harmful sphingoid bases that could insert into the plasma membrane.

Activity at the bacterial membrane may also depend upon the structure and shape of the treatment lipids. Several lipid characteristics important for activity include: hydrophobicity; number, placement, and orientation of double bonds, ${ }^{52-53}$ and in fatty acids, the length of the carbon chain ${ }^{53-55}$ and the-OH group. ${ }^{54}$ Studies indicate that fatty acids with cis-double bonds are more active than fatty acids with transdouble bonds. ${ }^{53,56}$ A cis-bonded lipid would likely cause a fluidizing effect upon insertion into a bacterial plasma membrane.

Finally, we show that sapienic acid induces upregulation of a unique set of proteins that may provide clues to specific mechanisms of action. In our Western blot and 2D-DIGE analysis of sapienic acid-treated $P$. gingivalis, we found upregulated proteins important in various cellular processes including glycolysis, amino acid metabolic processes, microbial metabolism in diverse environments, acquisition and degradation of polypeptides, adhesion and other virulence factors. $P$. gingivalis exhibits several unique stress responses, dependent upon the type of stressor. Heat stress, ${ }^{57-64} \mathrm{O}_{2}$ oxidative stress, ${ }^{57,59,65} \mathrm{H}_{2} \mathrm{O}_{2}$ oxidative stress, ${ }^{57,65-66} \mathrm{pH}$ stress, ${ }^{59-60}$ heme limitation, ${ }^{67}$ EtOH stress ${ }^{60}$ and response to contact with epithelial cells ${ }^{68}$ all induce extensive and unique responses in $P$. gingivalis with very little overlap (Supplementary Table 5). These well-documented stress responses have very little in common with the response induced by sapienic acid treatment.

All these data combined suggest that with sapienic acid, there may be a quick two-step process leading to antimicrobial activity that appears to be time and sapienic acid concentration dependent. As $P$. gingivalis cells are exposed to sapienic acid they begin taking up large amounts of the lipid, become stressed and quickly mount a response by adjusting protein activity, as evidenced by the differential protein profiles and the upregulation of several components important in microbial metabolism in diverse environments (e.g., glycerate dehydrogenase, nicotinamide adenine dinucleotide (NAD)-dependent glutamate dehydrogenase, glyceraldehydes 3-phosphate dehydrogenase and phosphoserine amino transferase). It is possible, however, that as a critical point (time and/or lipid concentration) is reached, rescue attempts fail and these cells succumb to lysis. Further analysis of the metabolic consequences of sapienic acid treatment on $P$. gingivalis will be necessary to confirm this and will possibly be the subject of future studies.

The 'self-disinfecting' properties of the skin have been recognized since 1942 when Burtenshaw described skin lipids that were active against a number of bacteria. ${ }^{21}$ Recent studies indicate that fatty acids and sphingoid bases function as innate immune molecules on the skin, ${ }^{11,69}$ oral mucosa ${ }^{70}$ and in other body fluids such as breast milk ${ }^{71-72}$ and sebum. ${ }^{73}$ In addition, lipid deficiencies or imbalances in lipid ratios are associated with several diseases. For example, both deficient hexadecanoic acid production ${ }^{74}$ and decreased levels of sphingo$\operatorname{sine}^{75}$ are associated with atopic dermatitis and subsequent increase in $S$. aureus skin colonization within otherwise healthy individuals. In addition, cystic fibrosis is linked with abnormal fatty acid metabolism. ${ }^{76-77}$ In another study, failure to clear skin infections of Staphylococus aureus or Streptococcus pyogenes within innate immunodeficient mice was linked to mutation of an enzyme necessary for palmitoleic and oleic acid production. ${ }^{78}$ Based on this information, it is possible that imbalances in lipid ratios or defective production of certain lipids could be responsible for other skin and oral diseases but this has yet to be determined. It becomes reasonable then to speculate that topical application of endogenous lipid formulations could potentially supplement the natural immune function of lipids on skin and other mucosal surfaces. ${ }^{79}$ 
With the increasing resistance of bacteria to many available antibiotic treatments ${ }^{79}$ it becomes more important to look for alternative treatments. Undecylenic acid has been used in over-the-counter antifungal preparations for several years. ${ }^{80-81}$ Hydrogels containing lipid suspensions are also appearing in the literature as topical treatments for a variety of viruses and bacteria ${ }^{82-83}$ and have been used in mice with no apparent irritation or toxic side effects. ${ }^{83}$ Clinical use of endogenous lipids would have several advantages over other antibiotic treatments. Drake et al. ${ }^{11}$ point out that because they are normal occupants of the skin [and oral mucosa] lipids are likely to be less irritating. In addition, because of their evolution with the potential pathogens of skin and oral mucosa it is more unlikely that these pathogens will readily develop resistance to treatment. ${ }^{11}$ Additionally, fatty acids and sphingoid bases used in our studies were active within normal physiologic ranges $\left(4.0-13.2 \mu \mathrm{g} \cdot \mathrm{mL}^{-1}\right.$ for total fatty acids and $0.5-$ $5.0 \mu \mathrm{g} \cdot \mathrm{mL}^{-1}$ for free long-chain bases) ${ }^{12-13}$ and would therefore be effective in tolerable concentrations.

Crucial to the development of formulations that would stimulate the natural innate function is a better understanding of the spectrum of fatty acid and sphingoid base activities and mechanisms of action. Knowledge of mechanisms behind the antimicrobial activity of antibacterial lipids is sparse and these data contribute to the available information.

\section{ACKNOWLEDGEMENTS}

The authors would like to acknowledge and thank Hongjin Huang, of Applied Biomics, Inc. (Hayward, CA, USA) for her help with the 2D-DIGE analysis and Joel Nott, of the Iowa State Protein Facility for his help with the sequencing of our Western blot data. This work was supported by the National Institute of Dental and Craniofacial Research, National Institutes of Health, R01 DEO18032 and R01 DEO14390.

1 Berglundh T, Donati M. Aspects of adaptive host response in periodontitis. J Clin Periodontol 2005; 32(6 Suppl): 87-107.

2 Eke PI, Dye BA, Wei L et al. Prevalence of periodontitis in adults in the United States: 2009 and 2010. J Dent Res 2012; 91(10): 914-920.

3 Socransky SS, Haffajee AD. The bacterial etiology of destructive periodontal disease: current concepts. J Periodontol 1992; 63(4 Suppl): 322-331.

4 Socransky SS, Haffajee AD, Cugini MA et al. Microbial complexes in subgingival plaque. J Clin Periodontol 1998; 25(2): 134-144.

5 Hutter G, Schlagenhauf U, Valenza G et al. Molecular analysis of bacteria in periodontitis: evaluation of clone libraries, novel phylotypes and putative pathogens. Microbiolog 2003; 149(Pt 1): 67-75

6 Kolenbrander PE, Andersen RN, Blehert DS et al. Communication among oral bacteria. Microbiol Mol Biol Rev 2002; 66(3): 486-505.

7 Holt SC, Kesavalu L, Walker S et al. Virulence factors of Porphyromonas gingivalis. Periodontol 2000 1999; 20: 168-238.

8 Gorr SU. Antimicrobial peptides in periodontal innate defense. Front Oral Biol 2012; 15: 84-98.

9 Gorr SU. Antimicrobial peptides of the oral cavity. Periodontol 2000 2009; 51: 152 180.

10 Bibel DJ, Aly R, Shah S et al. Sphingosines: antimicrobial barriers of the skin. Acta Derm Venereol 1993; 73(6): 407-411.

11 Drake DR, Brogden KA, Dawson DV et al. Thematic review series: skin lipids Antimicrobial lipids at the skin surface. J Lipid Res 2008; 49(1): 4-11.

12 Brasser A, Barwacz C, Bratt CL et al. Free sphingosine in human saliva. J Dent Res 2011; 90(Spec A): 3465.

13 Brasser AJ, Barwacz CA, Dawson DV et al. Presence of wax esters and squalene in human saliva. Arch Oral Biol 2011; 56(6): 588-591.

14 Law SL, Squier CA, Wertz PW. Free sphingosines in oral epithelium. Comp Biochem Physiol B Biochem Mol Biol 1995; 110(3): 511-513.

15 Law S, Wertz PW, Swartzendruber DC et al. Regional variation in content, composition and organization of porcine epithelial barrier lipids revealed by thin-layer chromatography and transmission electron microscopy. Arch Oral Biol 1995; 40(12): 1085-1091.

16 Smith KR, Thiboutot DM. Thematic review series: skin lipids. Sebaceous gland lipids: friend or foe? J Lipid Res 2008; 49(2): 271-281.

17 Zouboulis CC. Acne and sebaceous gland function. Clin Dermatol 2004; 22(5): 360366.
18 Zouboulis CC, Baron JM, Bohm M et al. Frontiers in sebaceous gland biology and pathology. Exp Dermatol 2008; 17(6): 542-551.

19 Bergsson G, Steingrimsson O, Thormar H. Bactericidal effects of fatty acids and monoglycerides on Helicobacter pylori. Int J Antimicrob Agents 2002; 20(4): 258262.

20 Bergsson G, Arnfinnsson J, Steingrimsson 0 et al. Killing of Gram-positive cocci by fatty acids and monoglycerides. APMIS 2001; 109(10): 670-678.

21 Burtenshaw JM. The mechanism of self-disinfection of the human skin and its appendages. J Hyg (Lond) 1942; 42(2): 184-210.

22 Bibel DJ, Aly R, Shinefield HR. Antimicrobial activity of sphingosines. J Invest Dermatol 1992; 98(3): 269-273.

23 Kalfa VC, Jia HP, Kunkle RA et al. Congeners of SMAP29 kill ovine pathogens and induce ultrastructural damage in bacterial cells. Antimicrob Agents Chemother 2001; 45(11): 3256-3261

24 Bratt $\mathrm{CL}$, Kohlgraf KG, Yohnke $\mathrm{K}$ et al. Communication: antimicrobial activity of SMAP28 with a targeting domain for Porphyromonas gingivalis. Probiotics Antimicrob Proteins 2010; 2(1): 21-25.

25 Weistroffer PL, Joly S, Srikantha R et al SMAP29 congeners demonstrate activity against oral bacteria and reduced toxicity against oral keratinocytes. Oral Microbiol Immunol 2008; 23(2): 89-95.

26 Brogden KA, Kalfa VC, Ackermann MR et al. The ovine cathelicidin SMAP29 kills ovine respiratory pathogens in vitro and in an ovine model of pulmonary infection. Antimicrob Agents Chemother 2001; 45(1): 331-334.

27 Drake DR, Wiemann AH, Rivera EM et al. Bacterial retention in canal walls in vitro: effect of smear layer. J Endod 1994; 20(2): 78-82.

28 Wertz PW, Swartzendruber DC, Madison KC et al. Composition and morphology of epidermal cyst lipids. J Invest Dermatol 1987; 89(4): 419-425.

29 Folch J, Lees M, Sloane Stanley GH. A simple method for the isolation and purification of total lipides from animal tissues. J Biol Chem 1957; 226(1): 497-509.

30 Wertz PW, Downing DT. Free sphingosines in porcine epidermis. Biochim Biophys Acta 1989; 1002(2): 213-217.

31 Weerheim A, Ponec M. Determination of stratum corneum lipid profile by tape stripping in combination with high-performance thin-layer chromatography. Arch Dermatol Res 2001; 293(4): 191-199.

32 Mun J, Onorato A, Nichols FC et al. Structural confirmation of the dihydrosphinganine and fatty acid constituents of the dental pathogen Porphyromonas gingivalis. Org Biomol Chem 2007; 5(23): 3826-3833.

33 Nichols FC, Riep B, Mun J et al. Structures and biological activities of novel phosphatidylethanolamine lipids of Porphyromonas gingivalis. J Lipid Res 2006; 47(4): 844-853.

34 Nichols FC, Riep B, Mun J et al. Structures and biological activity of phosphorylated dihydroceramides of Porphyromonas gingivalis. J Lipid Res 2004; 45(12): 2317 2330

35 Nichols FC. Novel ceramides recovered from Porphyromonas gingivalis: relationship to adult periodontitis. J Lipid Res 1998; 39(12): 2360-2370.

36 Conover WJ. Practical nonparametric statistics. 3rd ed. New York: Wiley, 1999.

37 Dawson DV, Siegler IC. Approaches to the nonparametric analysis of limited longitudinal data sets. Exp Aging Res 1996; 22(1): 33-57.

38 Ghosh M, Grizzle J, Sen PK. Nonparametric methods in longitudinal studies. J Am Stat Assoc 1973; 68(341): 29-36.

39 Mansheim BJ, Coleman SE. Immunochemical differences between oral and nonora strains of Bacteroides asaccharolyticus. Infect Immun 1980; 27(2): 589-596.

40 Mayrand D, Holt SC. Biology of asaccharolytic black-pigmented Bacteroides species. Microbiol Rev 1988; 52(1): 134-152.

41 Parent R, Mouton C, Lamonde L et al. Human and animal serotypes of Bacteroides gingivalis defined by crossed immunoelectrophoresis. Infect Immun 1986; 51(3): 909-918.

42 McBain AJ, Ledder RG, Sreenivasan P et al. Selection for high-level resistance by chronic triclosan exposure is not universal. J Antimicrob Chemother 2004; 53(5): 772-777.

43 do Amorim CV, Aun CE, Mayer MP. Susceptibility of some oral microorganisms to chlorhexidine and paramonochlorophenol. Braz Oral Res 2004; 18(3): 242-246.

44 Fischer CL, Drake DR, Dawson DV et al. Antibacterial activity of sphingoid bases and fatty acids against Gram-positive and Gram-negative bacteria. Antimicrob Agents Chemother 2012; 56(3): 1157-1161.

45 Fischer CL, Walters KS, Drake DR et al. Sphingoid bases are taken up by Escherichia coli and Staphylococcus aureus and induce ultrastructural damage. Skin Pharmacol Physiol 2013; 26(1): 36-44.

46 Khulusi S, Ahmed HA, Patel $\mathrm{P}$ et al. The effects of unsaturated fatty acids on Helicobacter pylori in vitro. J Med Microbiol 1995; 42(4): 276-282.

47 Brogden KA, De Lucca AJ, Bland J et al. Isolation of an ovine pulmonary surfactantassociated anionic peptide bactericidal for Pasteurella haemolytica. Proc Natl Acad Sci U S A 1996; 93(1): 412-416

48 Harder J, Bartels J, Christophers E et al. Isolation and characterization of human beta defensin-3, a novel human inducible peptide antibiotic. J Biol Chem 2001; 276(8): 5707-5713

49 Shimoda M, Ohki K, Shimamoto Y et al. Morphology of defensin-treated Staphylococcus aureus. Infect Immun 1995; 63(8): 2886-2891.

50 Brogden K. Antimicrobial peptides: pore formers or metabolic inhibitors in bacteria? Nat Rev Microbiol 2005; 3(3): 238-250.

51 Desbois AP, Smith VJ. Antibacterial free fatty acids: activities, mechanisms of action and biotechnological potential. App/ Microbiol Biotechnol2010; 85(6): 1629-1642. 
52 Saito H, Tomioka H, Yoneyama T. Growth of group IV mycobacteria on medium containing various saturated and unsaturated fatty acids. Antimicrob Agents Chemother 1984; 26(2): 164-169.

53 Kabara JJ, Conley AJ, Truant JP. Relationship of chemical structure and antimicrobial activity of alkyl amides and amines. Antimicrob Agents Chemother 1972; 2(6): 492498.

54 Zheng CJ, Yoo JS, Lee TG et al. Fatty acid synthesis is a target for antibacterial activity of unsaturated fatty acids. FEBS Lett 2005; 579(23): 5157-5162.

55 Willett NP, Morse GE. Long-chain fatty acid inhibition of growth of Streptococcus agalactiae in a chemically defined medium. J Bacteriol 1966; 91(6): 2245-2250.

56 Galbraith H, Miller TB, Paton AM et al. Antibacterial activity of long chain fatty acid and the reversal with calcium, magnesium, ergocalciferol and cholesterol. J App/ Bacteriol 1971; 34(4): 803-813.

57 Shelburne CE, Gleason RM, Coulter WA et al. Differential display analysis of Porphyromonas gingivalis gene activation response to heat and oxidative stress. Oral Microbiol Immunol 2005; 20(4): 233-238.

58 Amano A, Sharma A, Sojar HT et al. Effects of temperature stress on expression of fimbriae and superoxide dismutase by Porphyromonas gingivalis. Infect Immun 1994; 62(10): 4682-4685.

59 Vayssier C, Mayrand D, Grenier D. Detection of stress proteins in Porphyromonas gingivalis and other oral bacteria by Western immunoblotting analysis. FEMS Microbiol Lett 1994; 121(3): 303-307.

60 Lu B, McBride BC. Stress response of Porphyromonas gingivalis. Oral Microbiol Immunol 1994; 9(3): 166-173.

61 Percival RS, Marsh PD, Devine DA et al. Effect of temperature on growth, hemagglutination, and protease activity of Porphyromonas gingivalis. Infect Immun 1999; 67(4): 1917-1921.

62 Murakami Y, Masuda T, Imai M et al. Analysis of major virulence factors in Porphyromonas gingivalis under various culture temperatures using specific antibodies. Microbiol Immunol 2004; 48(8): 561-569.

63 Bonass WA, Marsh PD, Percival RS et al. Identification of ragAB as a temperatureregulated operon of Porphyromonas gingivalis W50 using differential display of randomly primed RNA. Infect Immun 2000; 68(7): 4012-4017.

64 Lopatin DE, Jaramillo E, Edwards CA et al. Cellular localization of a Hsp90 homologue in Porphyromonas gingivalis. FEMS Microbiol Lett 1999; 181(1): 9-16.

65 Meuric V, Gracieux P, Tamanai-Shacoori Z et al. Expression patterns of genes induced by oxidative stress in Porphyromonas gingivalis. Oral Microbiol Immunol 2008; 23(4): 308-314.

66 Vanterpool E, Aruni AW, Roy F et al. regT can modulate gingipain activity and response to oxidative stress in Porphyromonas gingivalis. Microbiology 2010; 156(Pt 10): 3065-3072.

67 Dashper SG, Ang CS, Veith PD et al. Response of Porphyromonas gingivalis to heme limitation in continuous culture. J Bacteriol 2009; 191(3): 1044-1055.

68 Hosogi Y, Duncan MJ. Gene expression in Porphyromonas gingivalis after contact with human epithelial cells. Infect Immun 2005; 73(4): 2327-2335.
69 Brogden KA, Drake DR, Dawson DV et al. Antimicrobial lipids of the skin and oral mucosa. // Dayan N, Wertz PW. Innate immune system of skin and oral mucosa. Hoboken: John Wiley \& Sons, Inc., 2011:75-81.

70 Bratt CL, Dawson D, Drake D et al. Oral mucosal lipids: antibacterial activity and induction of ultrastructural damage. J Dent Res 2010; 89(Spec A): 679.

71 Hosea Blewett HJ, Cicalo MC, Holland CD et al. The immunological components of human milk. Adv Food Nutr Res 2008; 54: 45-80.

72 Field CJ. The immunological components of human milk and their effect on immune development in infants. J Nutr 2005; 135(1): 1-4.

73 Wille JJ, Kydonieus A. Palmitoleic acid isomer (C16:1delta6) in human skin sebum is effective against Gram-positive bacteria. Skin Pharmacol Appl Skin Physiol 2003; 16(3): 176-187.

74 Takigawa $\mathrm{H}$, Nakagawa $\mathrm{H}$, Kuzukawa $\mathrm{M}$ et al. Deficient production of hexadecenoic acid in the skin is associated in part with the vulnerability of atopic dermatitis patients to colonization by Staphylococcus aureus. Dermatology 2005; 211(3): 240-248.

75 Arikawa J, Ishibashi M, Kawashima M et al. Decreased levels of sphingosine, a natura antimicrobial agent, may be associated with vulnerability of the stratum corneum from patients with atopic dermatitis to colonization by Staphylococcus aureus. J Invest Dermatol 2002; 119(2): 433-439.

76 Strandvik B, Gronowitz E, Enlund F et al. Essential fatty acid deficiency in relation to genotype in patients with cystic fibrosis. J Pediatr 2001; 139(5): 650-655.

77 Freedman SD, Blanco PG, Zaman MM et al. Association of cystic fibrosis with abnormalities in fatty acid metabolism. N Eng/ J Med 2004; 350(6): 560-569.

78 Georgel P, Crozat K, Lauth X et al. A Toll-like receptor 2-responsive lipid effector pathway protects mammals against skin infections with gram-positive bacteria. Infect Immun 2005; 73(8): 4512-4521.

79 Thormar $\mathrm{H}$, Hilmarsson $\mathrm{H}$. The role of microbicidal lipids in host defense against pathogens and their potential as therapeutic agents. Chem Phys Lipids 2007; 150(1): 1-11.

80 Anon. Undecylenic acid. Monograph. Altern Med Rev 2002; 7(1): 68-70.

81 Shapiro AL, Rothman S. August 1945: undecylenic acid in the treatment of dermatomycosis. Arch Dermatol 1983; 119(4): 345-350.

82 Thormar H, Bergsson G, Gunnarsson E et al. Hydrogels containing monocaprin have potent microbicidal activities against sexually transmitted viruses and bacteria in vitro. Sex Transm Infect 1999; 75(3): 181-185.

83 Neyts J, Kristmundsdottir T, de Clercq E et al. Hydrogels containing monocaprin prevent intravaginal and intracutaneous infections with HSV-2 in mice: impact on the search for vaginal microbicides. J Med Virol 2000; 61(1): 107-110.

(c) This work is licensed under a Creative Commons Attribution-NonCommercial-NoDerivative Works 3.0 Unported License. To view a copy of this license, visit http:// creativecommons.org/licenses/by-nc-nd/3.0 